\title{
Dihydroorotate Dehydrogenase (Quinone), Mitochondrial
}

National Cancer Institute

\section{Source}

National Cancer Institute. Dihydroorotate Dehydrogenase (Quinone), Mitochondrial. NCI

Thesaurus. Code C17289.

Dihydroorotate dehydrogenase (quinone), mitochondrial (395 aa, $43 \mathrm{kDa}$ ) is encoded by the human $\mathrm{DHODH}$ gene. This protein plays a role in the biosynthesis of pyrimidines. 